\footnotetext{
${ }^{1}$ Paléoenvironnement et Paléobiosphère, UMR 5125, CNRS, Université Lyon 1, Campus de la Doua, Villeurbanne, France;

${ }^{2}$ Anthropologisches Institut \& Museum Universität Zürich-Irchel Winterthurerstrasse 190, 8057 Zürich, Switzerland; ${ }^{3}$ Centre de Biologie et Gestion des Populations (INRA/IRD/Cirad/Montpellier SupAgro), Campus international de Baillarguet, Montferriersur-Lez Cedex, France; ${ }^{4}$ Centre de Biologie et Gestion des Populations (INRA/IRD/Cirad/Montpellier SupAgro), Campus international de Baillarguet, Montferrier-sur-Lez Cedex, France/Génétique des micro-organismes, University of Liège, Institute of Botany (Bat. 22) 4000 Liège, Belgium; ${ }^{5}$ Laboratoire de Biométrie et Biologie Evolutive, UMR 5558, CNRS, Université Lyon 1, Campus de la Doua, Villeurbanne, France
}

\title{
Can tooth differentiation help to understand species coexistence? The case of wood mice in China
}

\author{
Ronan Ledevin ${ }^{1,2}$, Jean-Pierre Quéré ${ }^{3}$, Johan R. Michaux ${ }^{4}$ and Sabrina Renaud ${ }^{5}$
}

\begin{abstract}
Five wood mice Apodemus species occur across China, in allopatry but also in sympatry up to cases of syntopy. They all share a similar external appearance, similar habitats of grasslands and forests and a generalist feeding behaviour. This overall similarity raises questions about the mechanisms insuring competition avoidance and allowing the coexistence of the species. In this context, a morphometric analysis of two characters related to feeding (mandible and molar) addressed the following issues: (1) Were the species actually different in size and/or shape of these characters, supporting their role in resource partitioning? (2) Did this pattern of phenotypic divergence match the neutral genetic differentiation, suggesting that differentiation might have occurred in a former phase of allopatry as a result of stochastic processes? (3) Did the species provide evidence of character displacement when occurring in sympatry, supporting an ongoing role of competition in the interspecific divergence? Results evidenced first that different traits, here mandibles and molars, provided discrepant pictures of the evolution of the Apodemus group in China. Mandible shape appeared as prone to vary in response to local conditions, blurring any phylogenetic or ecological pattern, whereas molar shape evolution appeared to be primarily driven by the degree of genetic differentiation. Molar size and shape segregated the different species in the morphospace, suggesting that these features may be involved in a resource partitioning between Apodemus species. The morphological segregation of the species, likely achieved by processes of differentiation in isolation promoted by the complex landscape of China, could contribute to competition avoidance and hence explain why no evidence was found of character displacement.
\end{abstract}

Key words: Morphometrics - mandible - molar - Apodemus - resource partitioning

\section{Introduction}

Asiatic regions of the world, despite being still largely understudied when compared with European areas, are more and more emerging as biodiversity hotspots (Liu et al. 2003; Sodhi et al. 2004). Although south-east Asia concentrates most interest because its tropical habitats appear prone to discover rare and sometimes highly emblematic species (e.g. Dawson et al. 2006; Huchon et al. 2007), more temperate regions like China also present a less emblematic but valuable and endangered biodiversity (Amori and Gippoliti 2001; Liu et al. 2003). How such a wealth of species, sometimes very similar based on external criteria, emerged and was maintained through time despite putative competition for resources is a challenging topic bringing together evolutionary and ecological issues.

Wood mice of the genus Apodemus (Kaup, 1829) appear as valuable models to tackle such questions. Five species occur across China: Apodemus agrarius (Pallas, 1771), A. draco (Barrett-Hamilton, 1900), A. latronum (Thomas, 1911), A. peninsulae (Thomas, 1907) and A. uralensis (Pallas, 1811) (Fig. 1). Their time of divergence is variable, from ca. $6 \mathrm{Ma}$ for the split between $A$. uralensis, belonging to the subgenus Sylvaemus, and

Corresponding author: Sabrina Renaud (sabrina.renaud@univlyon1.fr)

Contributing authors; Ronan Ledevin (ledevin_ronan@yahoo.fr), JeanPierre Quéré (quere@supagro.inra.fr), Johan R. Michaux (michaux@supagro.inra.fr) the four other species belonging to the subgenus Apodemus, to around $2 \mathrm{Ma}$ for the sister species $A$. draco and A. latronum. Despite the quite ancient divergence in some cases, these species are so remarkably similar based on external criteria that any reliable identification requires a confirmation using molecular markers (Giraudoux et al. 2008). Such a morphological similarity maintained over millions of years of evolution might be the result of stabilizing selection, but this challenges the question of how such species do coexist when occurring in sympatry and even in syntopy. Such coexistence suggests the existence of mechanisms insuring competition avoidance. Candidate factors include a differentiation related to the feeding apparatus, allowing for a differential exploitation of apparently similar resources (Dayan and Simberloff 1994; Dayan et al. 1990; Parra et al. 1999).

The size and shape of two characters evidently related to the feeding behaviour were thus quantified using geometric morphometrics methods: the mandible and the molar (first upper molar, M1) on Apodemus mice from a set of six localities across China (Fig. 1) documenting both cases of allopatry (A. agrarius in Ben Ben Wan, A. peninsulae in Baihaba and Rangtang, A. uralensis in Narati) and sympatry (A. agrarius and $A$. peninsulae in Xiji; $A$. draco, latronum and peninsulae in Maerkang).

Based on the quantification of the phenotypic traits, several questions were addressed to elucidate the mechanisms involved in the differentiation and coexistence of the Apodemus species in China. (1) Were the species actually diverging in size and/or 
shape of these characters, supporting their role in resource partitioning? (2) Did this pattern of phenotypic divergence match the expectation of neutral genetic differentiation, suggesting that differentiation might have occurred in a former phase of allopatry as a result of stochastic processes? This would not preclude the fact that morphological differentiation might contribute to the exploitation of slightly different resources and hence contribute to favour coexistence of species when coming later into secondary contacts. (3) Did the species still provide evidence of character displacement when occurring in sympatry, supporting an ongoing role of competition in the interspecific divergence?

\section{Material and Methods \\ Material}

A total of 126 wood mice were sampled in six localities documenting both cases of allopatry and sympatry (Table 1; Fig. 1). On these animals, 126 first upper molars and 83 mandibles were considered for morphometric analyses. All the animals were genetically identified (Sakka et al. 2010) and were considered as subadult or adult based on the fact that the third molar was erupted. This happens at around 3 weeks of age, a time corresponding to weaning.

Trapping sites encompassed a wide range of habitats, from fields and grasslands to forests, exemplifying the ecological diversity of the Apodemus mice. Maerkang habitat was dominated by forest. Baihaba, Xiji and Rangtang corresponded to open landscapes (bushes, fallows, scrubs). Narati and Ben Ben Wan presented mixed habitats with open fields and forest patches (Giraudoux et al. 1998, 2008; Raoul et al. 2008).

\section{Outline analysis of the mandible and first upper molar}

In murine rodents, the overall morphology of the mandible and molars is adequately described by their two-dimensional outline: regarding the mandible, the mandibular bone is almost flat and its outline describes the position and shape of its most prominent features, namely the processes of muscular insertion, the condyle and tooth-bearing alveolar region; regarding the molar, its outline close to the basis of the crown describes the position of the main cusps without being heavily affected by wear (Renaud 2005). For both features, outline analysis appeared as an efficient method to describe inter- and intraspecific variations in wood mice (Renaud and Millien 2001; Renaud and Michaux 2003, 2007; Renaud 2005).

\section{Mandible shape analysis}

The outline of the mandible corresponds to its projection, put flat with the lingual side down. Left mandibles were considered or mirror images of the right one when the left one was damaged. The starting point was defined at the meeting point of the incisor and the bone, at the antero-dorsal edge of the diastem. This outline was sampled by 64 points at equally spaced intervals. The mandible outline being complex, with re-entrant zones corresponding to the processes, it was analysed using an elliptic Fourier transform (EFT), a method well suited to the description of complex shape (Kuhl and Giardina 1982; Navarro et al. 2004). Any Fourier analysis decomposes an initial function of the outline in successive trigonometric functions of decreasing wavelength: the harmonics. The EFT is based on a separate decomposition of the incremental changes of the $x$ and $y$ coordinates as a function of the cumulative length along the outline. For each harmonic, 4 Fourier coefficients (FC) define an ellipse in the $x y$ plane: $A_{n}$ and $B_{n}$ for $x$ and $C_{n}$ and $D_{n}$ for $y$. The first harmonic ellipse corresponds to the best-fitting ellipse of the outline; its area is considered as size estimator of the outline and is used to standardize the other FCs for isometric size differences. Since the coefficients $A_{1}, B_{1}$ and $C_{1}$ correspond to residuals after this standardization (Crampton 1995; Renaud et al. 1996), they should not be included in the subsequent statistical analyses, to the contrary of the coefficient $D_{1}$ that still retains information about the elongation of the outline (Michaux et al. 2007).

\section{Molar shape analysis}

The two-dimensional outline of the first upper molar corresponds to its shape towards the basis of the crown. The starting point was tentatively located at the anteriormost part of the tooth. The outline was described by a set of 64 points at equal distances along the outline. The molar outline is simpler than the mandibular one and could be described using a simpler Fourier analysis than the EFT. Yet, some standardization properties of the EFT were used in the first place, using a procedure combining two Fourier approaches (Renaud et al. 2006).

The molar outline was first analysed an EFT procedure. The major axis of the first harmonic ellipse corresponds to the maximum elongation of the outline, coinciding with the anteroposterior elongation of the tooth. The first axis was thus used to adjust the starting point at the anteriormost part of the tooth in a comparable way among teeth. A reconstructed outline with an adjusted starting point was provided by this method, providing a new set of 64 points that were analysed using a radial Fourier transform (RFT). Using this method, a set of radii, that is, distance of each point to the centre of gravity of the outline, is calculated from the original coordinates and this set is then decomposed into Fourier functions. Each harmonic is thus described by two FCs $A_{n}$ and $B_{n}$ (Renaud and Michaux 2003). The zero harmonic corresponds to a best-fit circle to the outline and its value is used to standardize other FCs for isometric size differences.

\section{Threshold values of the Fourier analyses}

Whatever Fourier method considered, the higher the rank of the harmonic, the more detailed the description of the outline. Previous studies showed that considering the first nine harmonics offered a good compromise between measurement error, information content and the number of variables to be considered (Renaud et al. 1999). The shape of each mandible was thus described by a set of 33 FCs (4 EFT coefficients per 9 harmonics, minus $A_{1}, B_{1}$ and $C_{1}$ ) and the shape of each molar by a set of 18 FCs (2 RFT coefficients per 9 harmonics).

Table 1. Sampling localities of the Chinese wood mice considered in the present study. The abbreviation of each locality is provided (Code) as well as its latitude and longitude and administrative region. The number of measures is indicated for body size $(\mathrm{H}+\mathrm{B}$, head + body length), mandibles (Md) and first upper molars (M1) for each species present per locality

\begin{tabular}{|c|c|c|c|c|c|c|c|c|}
\hline Region & Locality & Code & Lat. & Long. & Species & $\mathrm{H}+\mathrm{B}$ & $\mathrm{Md}$ & M1 \\
\hline \multirow[t]{2}{*}{ Xinjiang } & Baihaba & Bai & 48.8 & 86.9 & A. peninsulae & 16 & 10 & 16 \\
\hline & Narati & Nar & 43.3 & 84.0 & A. uralensis & 34 & 23 & 34 \\
\hline Gansu & Ben Ben Wan & Bbw & 34.4 & 104.6 & A. agrarius & 12 & 7 & 12 \\
\hline \multirow{2}{*}{ Ningxia } & Xiji & $\mathrm{Xij}$ & 35.9 & 105.6 & A. agrarius & 16 & 9 & 16 \\
\hline & & & & & A. peninsulae & 3 & 3 & 3 \\
\hline \multirow[t]{4}{*}{ Sichuan } & Maerkang & Mae & 31.7 & 102.3 & A. draco & 17 & 15 & 17 \\
\hline & & & & & A. latronum & 14 & 7 & 14 \\
\hline & & & & & A. peninsulae & 2 & - & 2 \\
\hline & Rangtang & Ran & 32.3 & 101.1 & A. peninsulae & 12 & 9 & 12 \\
\hline
\end{tabular}


(a)

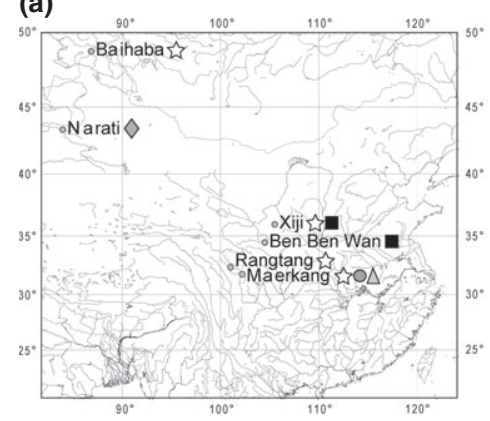

(b)

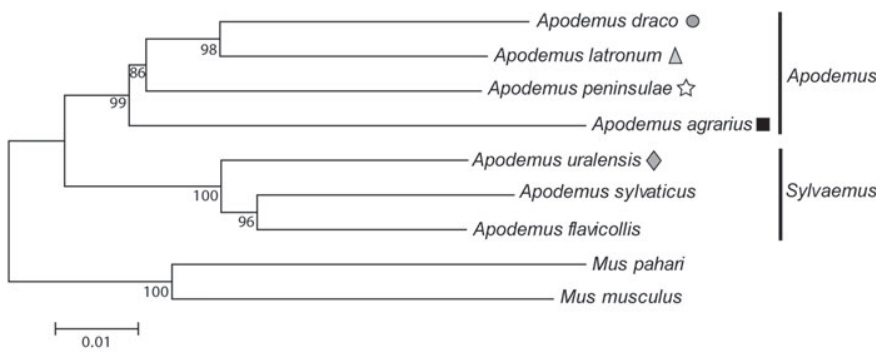

Fig. 1. Geographical and phylogenetic context of the study. (a) Map with the localities of trapping (grey dots). Symbols close to the name of the locality indicate the sampled species. (b) Phylogenetic relationships of the field and wood mice considered. The phylogenetic reconstruction was based on cytochrome $b$ (cyt $b$ ) and inter retinoid protein (IRBP) nuclear genes, all previously published in the literature and downloaded from the GenBank database (cyt $b$ accession numbers: JF819971, JF819970, FN430770, AF159390, AY389010, AY389003. GU908394, HQ256766, EU349767; IRBP: AB032860, AB032863, AB096853, AB096845, AB109398, AB096852, AB032857, AB033711, AB096855). These sequences correspond to the studied Chinese Apodemus species and two representatives of the Sylvaemus subgenus. Two Mus species were used as outgroups in the phylogenetic reconstruction. Cytochrome $b$ and IRBP sequences were combined to improve the robustness of the phylogenetic tree. MODELTEST 3.0 (Posada and Crandall 1998) was used to determine the most suitable model of DNA substitution for the combined cyt $b$ and IRBP data set studied. Phylogenetic reconstructions were performed using the maximum likelihood criterion (ML; Felsenstein 1981) implemented in PHYML (Guindon and Gascuel 2003). Phylogenetic trees were rooted with sequences from two Mus species. The robustness of the tree was assessed by bootstrap support (1000 random pseudoreplicates) (numbers are indicated on the nodes of the tree)

\section{Statistical analysis}

Univariate statistics

For each animal, different characters were considered that delivered several size estimates: (1) body size, estimated by the head + body length; (2) mandible size, estimated by the area enclosed by its twodimensional outline; and (3) the first upper molar, also estimated by its outline area. Relationships between these various size estimates were investigated using general linear models. Body size was considered as independent factor in relation to mandible and molar size; mandible size was considered as independent factor in relation to molar size. Analyses including all five species were first performed, with species as covariate and including the interaction of size per species. Analyses were then performed for each species separately. Inter- and intraspecific differences were tested using analyses of variance (ANOVA) complemented by non-parametric Kruskal-Wallis tests.

\section{Multivariate statistics}

For either the mandible or the molar, the FCs constituted shape variables that were analysed using multivariate statistics. The pattern of intra- and interspecific differentiation was displayed on the axes of a principal component analysis (PCA) performed on the variancecovariance matrix of the FCs. Such an analysis summarizes the total variance on a set of successive independent axes explaining a decreasing proportion of variance. Because of the large number of initial shape variables, the PCA was used to reduce the dimensionality of the data set for subsequent multivariate analyses (Sheets et al. 2006). Considering as new shape axes a set of first principal axes allows summarizing a maximum of shape variance on a minimum of independent variables. Two sets of principal axes were considered, cumulating more than $80 \%$ and more than $90 \%$ of the data set and termed thereafter PC80 and PC90, respectively. Intra- and interspecific differences were tested using multivariate analyses of variance (MANOVA, test considered: Wilks' Lambda) on the sets of FCs and on the sets of principal axes summarizing the total variance, PC80 and PC90.

\section{Sexual dimorphism}

The occurrence of sexual dimorphism was tested using analyses of variance (ANOVA) on univariate size variables and using MANOVA on multivariate data sets (PC80 and PC90).

\section{Congruence between data sets}

Several aspects of inter-specific shape differentiation were considered: relationship between shape and size and between mandible and molar shape. Relationships between shape and univariate parameters were tested using multivariate regressions, the independent variable being the mean size per locality and per species. Given the reduced number of items to be compared (8 group means when considering the mandible, 9 when considering the molar), the reduced shape data set (PC80) was the only one on which these tests could be performed. Even so, sample size was too low to apply this approach for assessing the relationship between the two multivariate data sets corresponding to mandible and molar shape. Mandible and molar patterns of shape differentiation were thus compared using correlation between matrices of Euclidean distances, using a Mantel $t$-test.

\section{Intergroup distances}

Euclidean distances were further calculated among group means (locality per species) for all characters considered: body size (head + body length), mandible and molar size (area of the outline) and mandible and molar shape (distances among mean Fourier coefficients). These distances were separated in three categories: distances among intraspecific pairs (pairs involving the same species in different localities); distances among interspecific pairs in allopatry; and distances among interspecific pairs in sympatry. An accumulation of morphological divergence together with neutral genetic divergence would be supported by intraspecific distances being smaller than interspecific distances. Character displacement would be supported by distances between species in sympatry being larger than the same species in allopatry (Adams et al. 2007).

Distances data sets corresponding to intraspecific, sympatric and allopatric pairs were compared visually and in percentage of divergence. Non-parametric Kruskal-Wallis tests were further used to compare distribution among categories of distances.

\section{Results}

\section{Sexual dimorphism}

The occurrence of sexual dimorphism was tested in each species for the body size and for the size and shape of the first upper molar and the mandible. A difference between sexes was evidenced in none of the species, for neither size nor shape (Table 2). This absence of sexual dimorphism on size and shape of phenotypic traits such as mandible and molars is in agreement with previous studies on wood mice (Renaud 2005). Therefore, males and females were pooled together in the subsequent analyses. 
Table 2. Test of sexual dimorphism in the five Chinese species of wood mice A. agrarius, A. draco, A. latronum, A. peninsulae and A. uralensis for body size (H $+\mathrm{B}$ : head + body length), mandibles (Md) and first upper molars (M1). Mandible and molar size was estimated by the outline area; shape was estimated by the first principal axes extracted from the complete set of Fourier coefficients, to reduce dimensionality of the data set. Two sets of axes were considered: summarizing more than $80 \%$ (Md, 4 PCs; M1, 5 PCs) and 90\% (Md, 6 PCs; M1, 8 PCs) of the total variance. Probabilities of ANOVA are given for univariate size variables, of MANOVA for multivariate shape data sets

\begin{tabular}{|c|c|c|c|c|c|c|c|}
\hline & $\mathrm{H}+\mathrm{B}$ & Md size & Md PC80 & Md PC90 & M1 size & M1 PC80 & M1 PC90 \\
\hline A. agrarius & 0.498 & 0.234 & 0.911 & 0.722 & 0.975 & 0.364 & 0.466 \\
\hline A. draco & 0.100 & 0.302 & 0.521 & 0.763 & 0.998 & 0.912 & 0.659 \\
\hline A. latronum & 0.370 & 0.299 & 0.571 & 0.834 & 0.301 & 0.192 & 0.167 \\
\hline A. peninsulae & 0.170 & 0.921 & 0.383 & 0.112 & 0.166 & 0.261 & 0.213 \\
\hline A. uralensis & 0.885 & 0.430 & 0.682 & 0.843 & 0.959 & 0.116 & 0.258 \\
\hline
\end{tabular}

\section{Intra- and interspecific size variations}

Relationships between size parameters

Three different measures of size were available for each animal, regarding different traits: body, mandible and molar. A global scaling is expected; yet, uncoupling within species may point to different selective contexts and/or constraints throughout the animal's life for the different characters. A significant effect of body size on mandible size was evidenced, together with specific differences and an interaction pointing to different body size - mandible size relationships in the different species (Table 3). This strong relationship was confirmed when analysing each species separately. In contrast, molar size was related to body size in none of the species. It was related to mandible size in A. draco and A. uralensis.

\section{Intraspecific size variations}

Apodemus agrarius and $A$. peninsulae were the only two species documented in more than one locality, thus allowing an investigation of intraspecific variations (Fig. 2; Table 4). Body size differences were limited in A. agrarius and could not be evidenced in $A$. peninsulae. Mandible size did not display any significant intraspecific differences, whereas molar size differed between localities in both species (Table 4).

\section{Interspecific size variations}

The five species were significantly different in body, mandible and molar size (Table 4), A. latronum being the largest species whatever size estimate considered. The smallest species in body size was $A$. draco, whereas $A$. uralensis displayed overall the smallest mandibles and teeth (Fig. 2).
Interspecific size differences between co-occurring species were further investigated in the two localities Xiji and Maerkang that delivered more than one species. A. agrarius and $A$. peninsulae were coexisting in Xiji; they appeared to share similar body, mandible and molar size (Table 4). Three species co-occur in Maerkang: A peninsulae and the two sister species A. draco and A. latronum. Significant differences in body and molar size were documented; differences in mandible size were marginal.

\section{Patterns of intra- and interspecific differentiation in mandible shape}

The PCA on the Fourier coefficients summarized the total variance on few successive axes. The first two PCs expressed more than $70 \%$ of the total variance, more than $80 \%$ was expressed when considering the first four axes and more than $90 \%$ when considering the first six axes $(\mathrm{PC} 1=42.2 \%$, $\mathrm{PC} 2=29.0 \%, \mathrm{PC} 3=8.5 \%, \mathrm{PC} 4=7.2 \%$, PC5 $=2.7 \%$, PC6 $=2.5 \%$, subsequent axes $<2 \%$ ). A complex pattern of mandible shape differentiation emerged on the morphospace defined by the first two principal axes of a PCA on the Fourier coefficients (Fig. 3). Variations along PC1 overall opposed wider mandibles with developed processes and a broad alveolar region (towards negative PC1) to slender mandibles. Variations along PC2 mostly corresponded to a relative development of the angular and coronoid processes.

Mandible shape was different among species (Table 4). Intraspecific differences were overall of limited importance and were only evidenced on reduced data sets in both $A$. agrarius

Table 3. Relationships between body, mandible and molar size in the five species of wood mice, tested using linear models

\begin{tabular}{|c|c|c|c|c|c|c|c|c|c|}
\hline & & $X$ & Y & & $X$ & Y & & $X$ & $Y$ \\
\hline & & $\mathrm{H}+\mathrm{B}$ & $\mathrm{Md}$ & & $\mathrm{H}+\mathrm{B}$ & M1 & & $\mathrm{Md}$ & M1 \\
\hline & $\mathrm{N}$ & $\mathrm{p}$ & $R$ & $N$ & $\mathrm{p}$ & $R$ & $N$ & $\mathrm{p}$ & $R$ \\
\hline \multicolumn{10}{|l|}{ Total } \\
\hline Size & 82 & 0.000 & 0.853 & 126 & 0.089 & 0.895 & 82 & 0.095 & 0.883 \\
\hline Species & & 0.000 & & & 0.074 & & & 0.096 & \\
\hline Size $\times$ species & & 0.000 & & & 0.378 & & & 0.116 & \\
\hline \multicolumn{10}{|l|}{ Per species } \\
\hline A. agrarius & 16 & 0.157 & 0.371 & 28 & 0.600 & 0.104 & 16 & 0.770 & 0.079 \\
\hline A. draco & 15 & 0.000 & 0.960 & 17 & 0.129 & 0.383 & 15 & 0.012 & 0.631 \\
\hline A. latronum & 7 & 0.034 & 0.790 & 14 & 0.945 & 0.020 & 7 & 0.914 & 0.051 \\
\hline A. peninsulae & 21 & 0.004 & 0.595 & 33 & 0.738 & 0.060 & 21 & 0.909 & 0.026 \\
\hline A. uralensis & 23 & 0.000 & 0.756 & 34 & 0.360 & 0.162 & 23 & 0.000 & 0.756 \\
\hline
\end{tabular}

$X$, independent variable; $Y$, dependent variable, $N$, number of items; $R$, coefficient of correlation; $\mathrm{p}$, probability in a linear model. $\mathrm{H}+\mathrm{B}$, head + body length; Md, mandible area; M1, molar area. In bold significant probabilities 

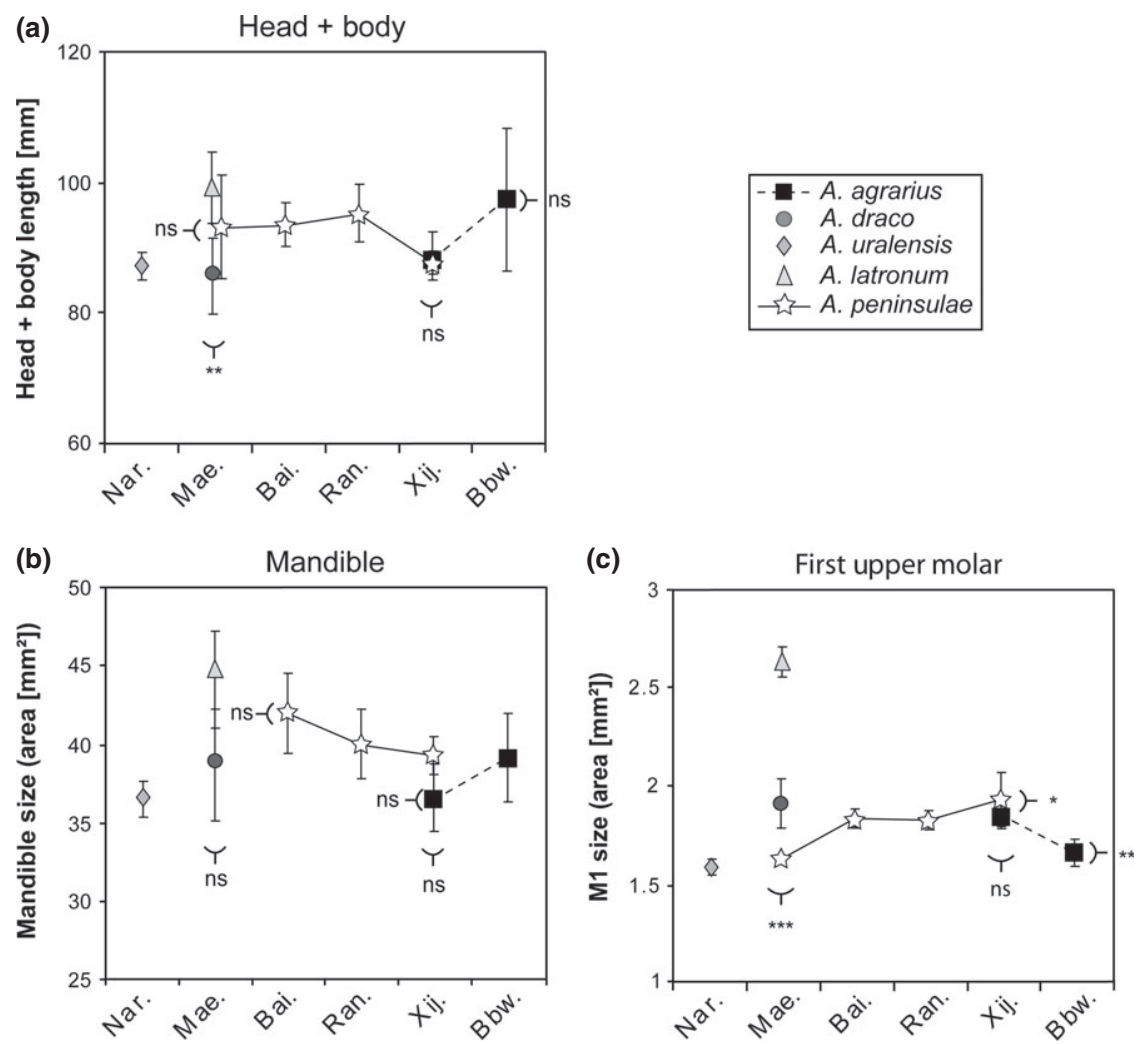

Fig. 2. Size variations of five Apodemus species across the different localities in China. (a) Body size, estimated by head + body length. Mandible size (b) and first upper molar size (c), estimated by the area of their outline. Average values per locality and species are plotted ( $\pm 95 \%$ confidence interval)

and A. peninsulae (Table 4). A striking feature was the importance of intra-group variability, as shown by the large confidence intervals surrounding each mean. Such a large variability tended to swamp out even interspecific differentiation that was weak at Maerkang and could not be evidenced at Xiji (Table 4).

Table 4. Intraspecific and interspecific differentiation in body size $(\mathrm{H}+\mathrm{B}$, head + body length) and size and shape of the mandible $(\mathrm{Md})$ and the molar (M1). Intraspecific differentiation was investigated for species sampled at more than one locality (A. agrarius and A. peninsulae). Interspecific differentiation was investigated between the five species and between sympatric species at localities where more than one species were sampled (Maerkang and Xiji). Probabilities of ANOva and of non-parametric Kruskal-Wallis (KW) tests are provided for univariate size parameters; for multivariate data sets, probabilities (Wilks' Lambda tests) of MANOvA are provided, performed on either the set of Fourier coefficients (FCs), the set of principal axes summarizing 80\% of variance (PC80; Md, 4 PCs; M1, 5 PCs) and 90\% of variance (PC90; Md, 6 PCs; M1, 8 PCs). In bold significant probabilities

\begin{tabular}{|c|c|c|c|c|c|}
\hline & \multicolumn{2}{|c|}{ Size } & \multirow[t]{2}{*}{ FCs } & \multirow{2}{*}{$\begin{array}{c}\text { PC80 } \\
\text { MANOVA }\end{array}$} & \multirow[t]{2}{*}{ PC90 } \\
\hline & ANOVA & KW & & & \\
\hline \multicolumn{6}{|l|}{$\mathrm{H}+\mathrm{B}$} \\
\hline 5 species & 0.000 & 0.000 & & & \\
\hline A. agrarius & 0.131 & 0.006 & & & \\
\hline A. peninsulae & 0.494 & 0.353 & & & \\
\hline Maerkang & 0.002 & 0.003 & & & \\
\hline Xiji & 0.882 & 0.736 & & & \\
\hline \multicolumn{6}{|l|}{$\mathrm{Md}$} \\
\hline 5 species & 0.000 & 0.000 & 0.0000 & 0.0000 & 0.0000 \\
\hline A. agrarius & 0.185 & 0.101 & 0.2857 & 0.0236 & 0.0468 \\
\hline A. peninsulae & 0.375 & 0.459 & 0.0753 & 0.0320 & 0.0968 \\
\hline Maerkang & 0.077 & 0.045 & 0.5020 & 0.0271 & 0.1033 \\
\hline Xiji & 0.217 & 0.116 & 0.5527 & 0.2521 & 0.4744 \\
\hline \multicolumn{6}{|l|}{ M1 } \\
\hline 5 species & 0.000 & 0.000 & 0.0000 & 0.0000 & 0.0000 \\
\hline A. agrarius & 0.002 & 0.003 & 0.0939 & 0.0583 & 0.1705 \\
\hline A. peninsulae & 0.013 & 0.065 & 0.0002 & 0.0000 & 0.0000 \\
\hline Maerkang & 0.000 & 0.000 & 0.0254 & 0.0000 & 0.0000 \\
\hline Xiji & 0.412 & 0.502 & 0.7265 & 0.0021 & 0.0128 \\
\hline
\end{tabular}



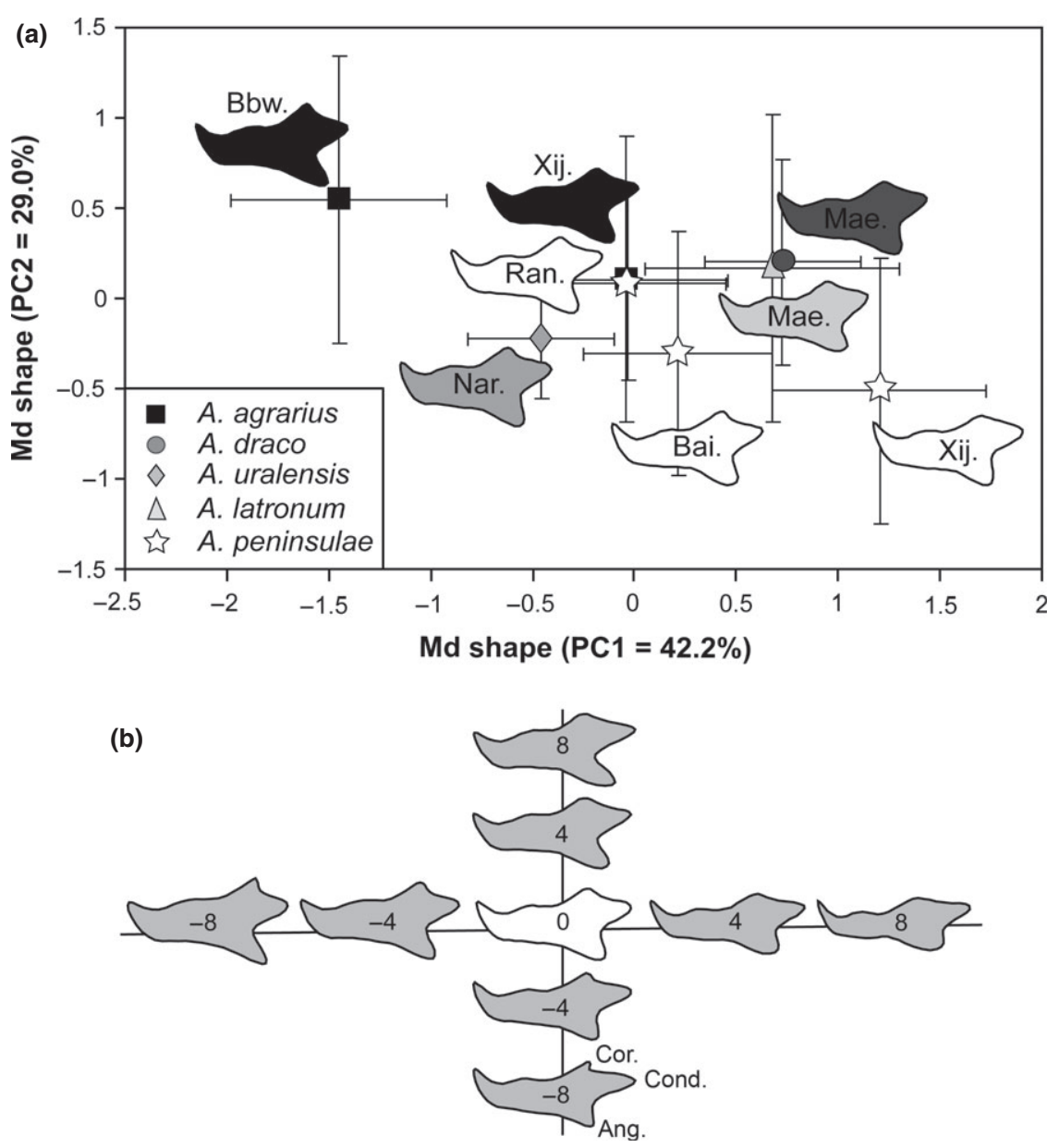

Fig. 3. Shape differentiation of the mandible among Apodemus species in China. (a) First two principal components (expressing $71.8 \%$ of the total variance) obtained by a PCA on the EFT Fourier coefficients of the mandible outline. (b) Shape changes along the axes. The white outline corresponds to the average shape, and grey outlines to exaggerated variations along the axes (scores $=4 /-4$ and $8 /-8$ ). Average values per locality and species are plotted ( $\pm 95 \%$ confidence interval) together with the corresponding mean outline

Patterns of intra- and interspecific differentiation in molar shape The first two axes of a PCA on the Fourier coefficients expressed more than $70 \%$ of the total variance, whereas subsequent axes explained each a relatively small amount of variance $(\mathrm{PC} 1=55.6 \%, \mathrm{PC} 2=10.0 \%, \mathrm{PC} 3=7.6 \%$, PC4 $=6.0 \%, \quad$ PC5 $=4.3 \%, \quad$ PC6 $=3.0 \%, \quad$ PC7 $=2.9 \%$, PC8 $=2.4$, subsequent axes $<2 \%$ ). Cumulating the first five PCs expressed more than $80 \%$ and the first eight axes more than $90 \%$.

The differentiation in molar shape on the first two PCs provided a clearer pattern than considering mandible shape (Fig. 4). The intragroup variability was much reduced and a strong interspecific differentiation emerged as the most important signal (MANOVA between species: $\mathrm{p}<0.0001$, on FCs as well as the reduced data sets PC80 and PC90). The most divergent species was $A$. agrarius, characterized by slender molars, opposed at the other extreme to $A$. peninsulae that displayed the broader molars. A. draco, A. uralensis and $A$. latronum were intermediate in molar shape, the two latter being close and relatively broad in shape, whereas the former tended to be closer to A. agrarius. This strong interspecific differentiation characterized the sympatric species in Maerkang as well as in Xiji (Table 4). Beyond this main pattern of interspecific differentiation, within species variations were not significant in A. agrarius but were highly significant in A. peninsulae. Within-species variation may be significant in this species because it is the only one documented by localities far apart, and the most distant locality (Baihaba, to the extreme north-west of China) indeed appeared as the most divergent.

\section{Relationship between patterns of differentiation of the different} characters

Patterns of intergroup differentiation were evaluated by mean values per locality and per species. Multiple regressions showed that body size differences were correlated neither with mandible shape (multivariate regression of size vs. PC80: $p=0.096$ ) nor with molar shape $(p=0.446)$. Intergroup differences in mandible size did not correlate with molar shape $(\mathrm{p}=0.879)$ but were weakly related with variations in mandible shape $(p=0.046)$

Patterns of differentiation observed for mandible shape and molar shape were not correlated (correlation among distance matrices, Mantel $t$-test on PC80: $R=-0.248$ ). 


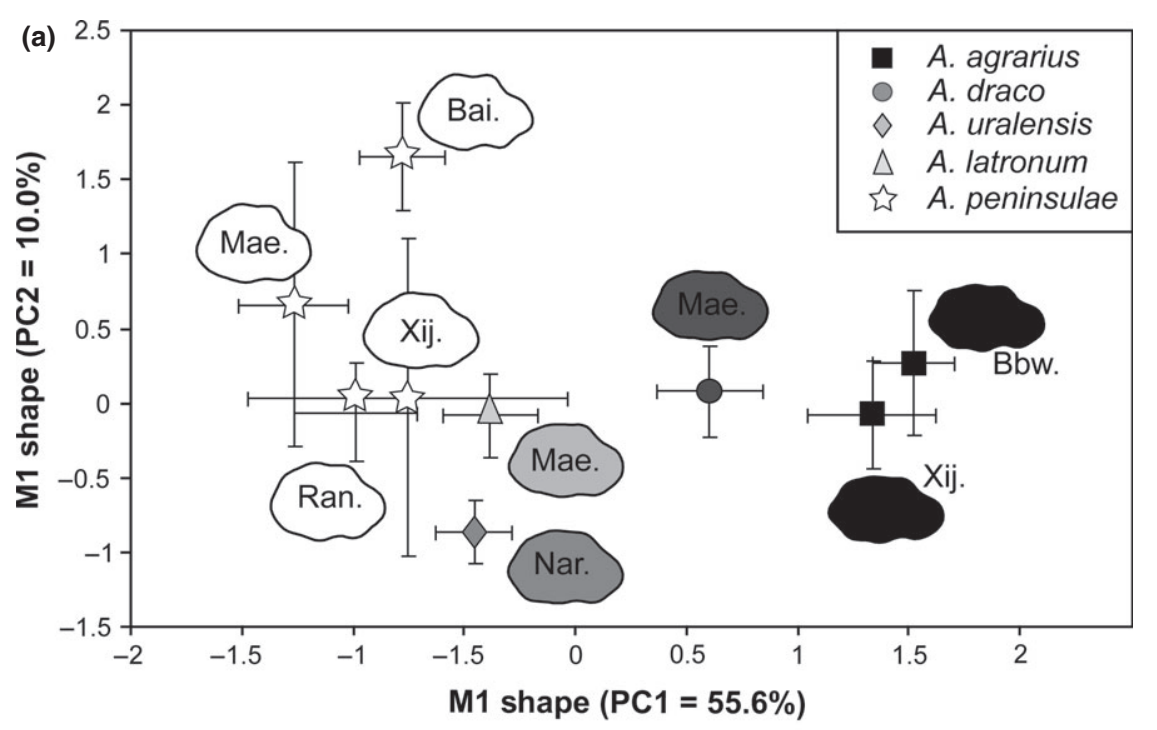

(b)

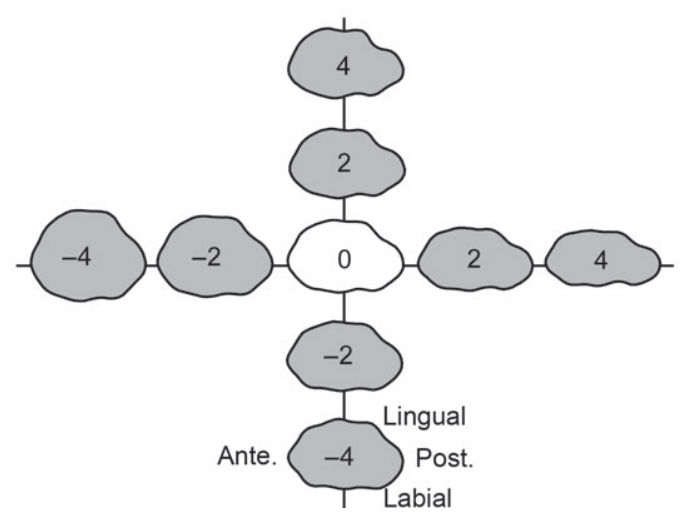

Fig. 4. Shape differentiation of the first upper molar among Apodemus species in China. (a) First two principal components (expressing $65.6 \%$ of the total variance) obtained by a PCA on the RFT Fourier coefficients of the M1 outline. (b) Shape changes along the axes. The white outline corresponds to the average shape, and grey outlines to exaggerated variations on the axes (scores $=2 /-2$ and $4 /-4$ ). Average values per locality and species are plotted $( \pm 95 \%$ confidence interval) together with the corresponding mean outline

Size and shape differentiation of the first upper molar across the localities

The previous results evidenced a complex pattern of size and shape differentiation, two aspects that together describe the whole form of a character. A combined visualization of the differentiation in size and shape was therefore attempted, focusing on the M1 that displayed much clearer interspecific differences in size (Fig. 2) and shape (Fig. 4) than the mandible.

Size was estimated by the area of the M1 and shape variations were summarized by scores along PC1, considered as a satisfying synthetic shape axis given the high amount of total variance explained by this axis $(56 \%)$.

In the two localities where sympatric species occur, the combination of size and shape allowed a complete segregation of the different species (Fig. 5). In Maerkang (Fig. 5a), molars of $A$. draco and $A$. peninsulae were of similar size but strongly differ in shape, whereas A. latronum, intermediate in shape, differed in molar size. In Xiji (Fig. 5b), A. peninsulae and $A$. agrarius displayed similar molar size, but were different in shape.

Furthermore, each species seemed to occupy a stable range of size and shape, either being found in sympatry (Maerkang,
Xiji) or alone in a locality (Fig. 5c-f). This was further investigated by comparing allopatric and sympatric size and shape distances.

\section{Morphological distances}

Among-group distances based on body size and on size and shape of mandible and molars were investigated between intraspecific pairs and interspecific pairs involving species in sympatry or in allopatry.

Intra-specific distances were in average smaller than interspecific distances for size and shape (Table 5). This difference was the most limited $(10 \%)$ for mandible shape and the most pronounced for molar size and shape (around 50\%). A difference in distribution was nevertheless only significant for molar shape $(\mathrm{p}=0.002)$ owing to a large dispersion in the set of interspecific allopatric distances (Fig. 6).

Within interspecific distances, allopatric and sympatric pairs were compared. No consistent pattern emerged across characters, distance in sympatry tending to be larger than in allopatry for size, but not for shape (Table 5). Yet, the distribution of distances in allopatry vs. in sympatry differed significantly in none of the cases. The large dispersion of 

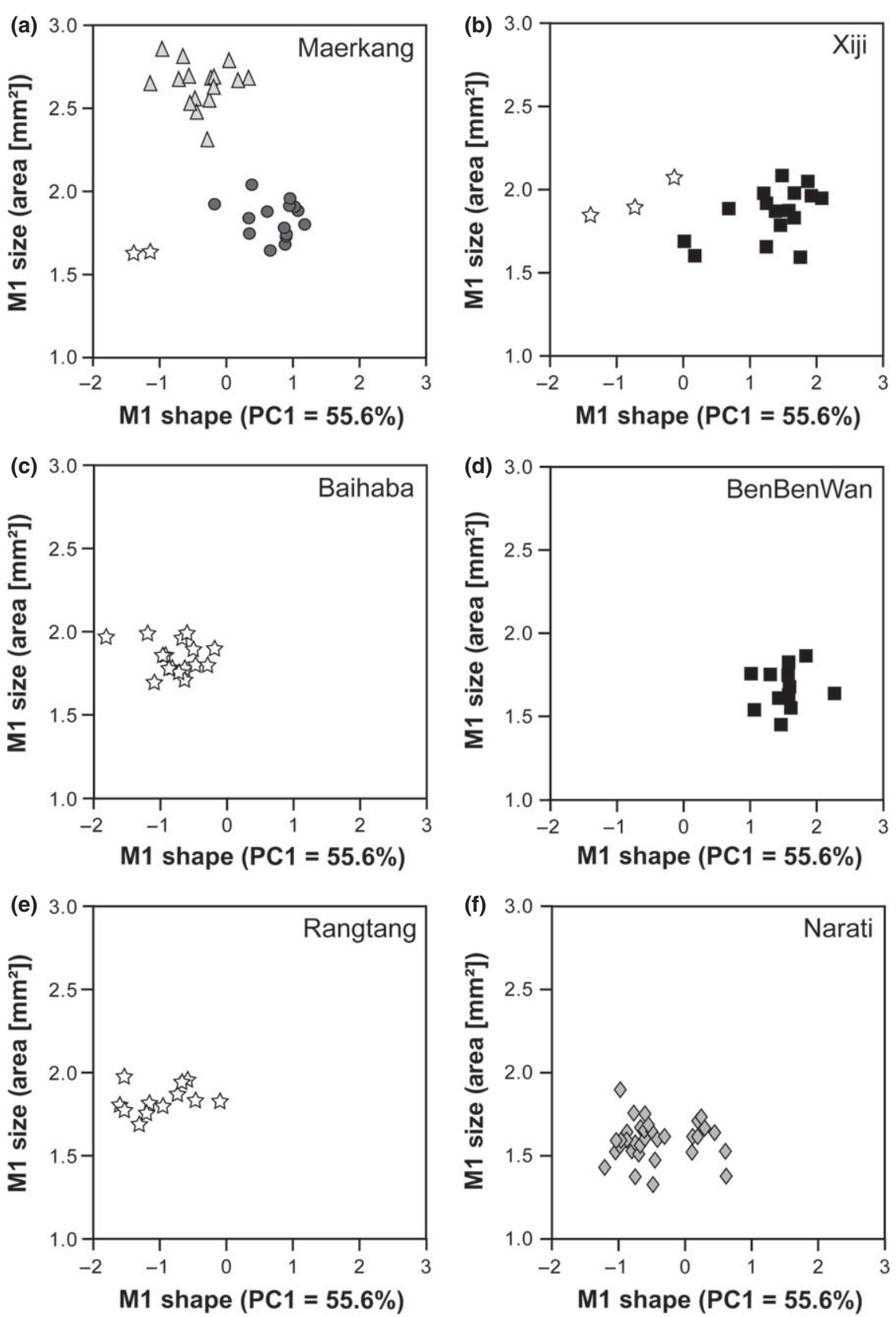
A. agrarius
A. uralensis
is A. peninsulae
A. draco
$\triangle$ A. latronum

Fig. 5. Size and shape of the first upper molars in the six localities of sampling: Maerkang (a), Xiji (b), Baihaba (c), BenBenWan (d), Rangtang (e) and Narati (f). The size is estimated by the area of the molar outline and the shape by the first principal component of a PCA (PC1 expressing $55.6 \%$ of the variance) on Fourier coefficients of the molar outline. Each dot corresponds to a specimen, and the symbols indicate the species

distances may be due to the involvement of different pairs between the five species sampled. Distances between allopatric and sympatric pairs were thus considered for A. agrarius and A. peninsulae only (Table 5), including a sympatric case and 7 allopatric cases ( 5 for the mandible). The distance in sympatry was close to the mean distance observed in allopatry for mandible size and shape, and molar shape and smaller (40-80\%) for body size and molar size. The distance in sympatry was the smallest of all $A$. agrarius $-A$. peninsulae distances for body size and intermingled with distances in allopatry in all other cases (Table 5).

\section{Discussion}

Phenotypic characters were traditionally important taxonomic characters; despite the preponderant importance nowadays of genetic studies for such purposes, morphological traits still constitute a valuable component of diversity to be considered together with genetics. Beyond practical interest for helping identification of animals on the field (e.g. Darviche and Orsini 1982; Darviche et al. 2006), morphological traits can constitute the most evident reason for recognizing divergent forms and may provide useful information in the assessment of conser- 
Table 5. Comparison of interspecific vs. intraspecific distances, and sympatric vs. allopatric distances for body size, and mandible and molar size and shape. Allopatric: interspecific distances between pairs in allopatry; sympatric: interspecific distances between pairs in sympatry; intraspecific: distances between localities of a same species. Euclidean distances calculated on body size $(\mathrm{H}+\mathrm{B})$, mandible $(\mathrm{Md})$ and molar $(\mathrm{M} 1)$ size, and mandible and molar shape (distances among Fourier coefficients). How much distances between sympatric pairs were larger than distances between allopatric pairs and how much intraspecific distances were larger than distances between interspecific allopatric pairs has been expressed in percentage of the mean interspecific allopatric differences (Symp-Allo\% and Intra-Inter\%, respectively). Lower panel: values for pairs involving $A$. agrarius and $A$. peninsulae only. Counts of cases where the distance in sympatry was larger than the distance in allopatry as expected based on character displacements are indicated (Symp $>$ Allo)

\begin{tabular}{|c|c|c|c|c|c|}
\hline & $\mathrm{H}+\mathrm{B}$ & MdSize & MdShape & M1size & M1Shape \\
\hline \multicolumn{6}{|l|}{ All pairs } \\
\hline Allopatric & 5.97 & 3.13 & 0.052 & 0.32 & 0.029 \\
\hline Sympatric & 7.12 & 4.02 & 0.042 & 0.52 & 0.029 \\
\hline Intraspecific & 4.27 & 1.97 & 0.048 & 0.16 & 0.015 \\
\hline Symp-Allo \% & 19 & 28 & -20 & 63 & -1 \\
\hline Intra-Inter \% & -28 & -37 & -9 & -50 & -48 \\
\hline \multicolumn{6}{|c|}{ A. agrarius - A. peninsulae } \\
\hline Allopatric & 4.85 & 2.50 & 0.058 & 0.13 & 0.044 \\
\hline Sympatric & 0.69 & 2.61 & 0.057 & 0.08 & 0.039 \\
\hline Symp-Allo \% & -86 & 5 & -3 & -39 & -12 \\
\hline Symp > Allo \# & $0 / 7$ & $2 / 5$ & $2 / 5$ & $3 / 7$ & $3 / 7$ \\
\hline
\end{tabular}
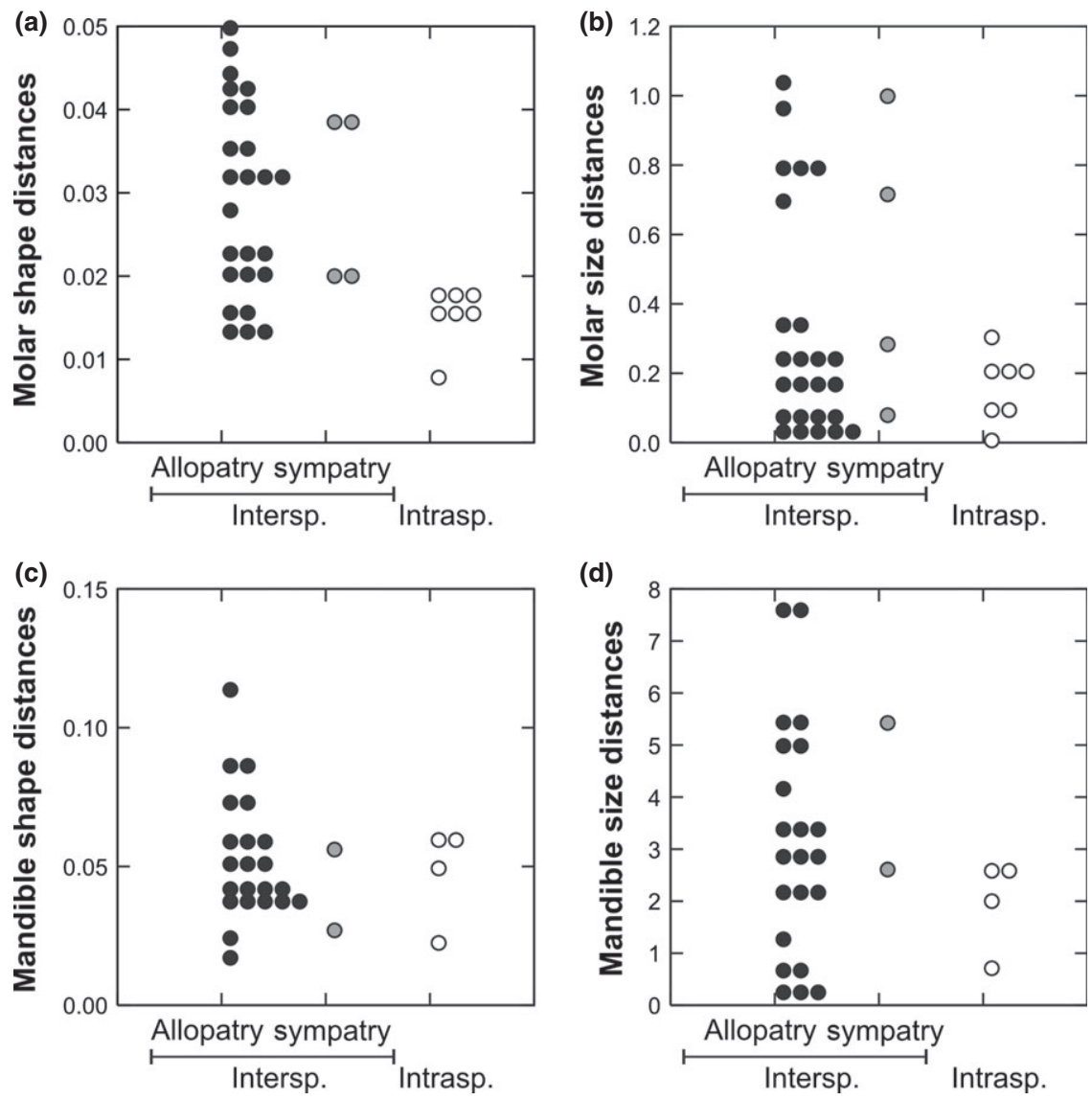

Fig. 6. Size and shape intergroup distances based on molar and mandible outline analysis. (a) Molar shape distances, that is, Euclidean distances between Fourier coefficients of the outline analysis. (b) Molar size distances, that is, Euclidean distance between molar outline average areas. (c) Mandible shape distances. (d) Mandible size distances. Interspecific comparisons are separated into allopatric (black circles) and sympatric (grey circles) pairs. Distances between pairs of the same species are represented by open circles

vation priorities (e.g. Cardini and O'Higgins 2004; Cardini et al. 2007). They also constitute a crucial aspect in evolution, because phenotypic traits are those that allow an animal to face its environment and as such, are those submitted to the screening by selection. They can thus provide valuable information about the selective context that drove evolution.

\section{Two characters, two stories of differentiation}

Different traits may be related to different functions and depend on various genetic, developmental and environmental factors. Hence, their patterns of differentiation may reflect different aspects of evolution. Indeed, a discrepancy between 
results based on mandible and molar shape emerged from our results. Intraspecific relative to interspecific variation was large when considering mandible shape but much weaker regarding the molar analysis. The sensitivity of the mandible shape to environmental influences has been repetitively evidenced (Renaud 2005; Rychlik et al. 2006). This morphological feature is prone to bone remodelling even during the post-weaning life on the animal, thus allowing significant differences in shape to accumulate because of plasticity (Renaud and Auffray 2010; Renaud et al. 2010). On the much longer timescale of the diversification of the murine family, the most important factor driving mandible differentiation appeared to be feeding ecology rather than phylogeny (Michaux et al. 2007). Hence, both plastic response and adaptation to local conditions over generations may contribute to the large intraspecific relative to interspecific variation in mandible morphology across sampling localities in China, corresponding to a wide variety of habitats, from forest to grassland and even farmland (Giraudoux et al. 1998, 2008; Raoul et al. 2008).

In contrast, molar shape appeared to be characterized by an important interspecific relative to intraspecific variation. Once erupted, molars are only prone to wear, a process only marginally affecting the crown outline (Renaud 2005), making them unlikely to vary in a plastic way within a generation (Renaud 2005; Rychlik et al. 2006) and hence less sensitive to direct environmental influences.

\section{Molar shape, a signal of genetic and/or ecological differentiation?}

The present study encompasses different scales of differentiation, from intra- to interspecific, hence ranging from less than a million years to above 6 million years for the oldest divergence. The importance of interspecific differences relative to intraspecific variation suggested that molar shape differentiation occurred parallel to genetic divergence during speciation. How does this pattern fit with the known phylogeny of the group? Two subgenera of Apodemus mice occur in China, A. uralensis being the sole representative of the Sylvaemus subgenus, whereas the other species belong to the Apodemus subgenus (Fig. 1; Suzuki et al. 2008). Within this latter group, A. agrarius and A.peninsulae diverged around $5 \mathrm{Ma}$ ago (Michaux et al. 2002; Suzuki et al. 2008). Finally, the sister species A. draco and A. latronum diverged only ca. 2 Ma ago (Suzuki et al. 2008).

As far as revealed by our sampling, this phylogenetic pattern fits well to the observed differentiation in molar shape, the most divergent species of the subgenus Apodemus, A. agrarius and $A$. peninsulae, being also characterized by the most differentiated molar shape, whereas the sister species $A$. draco and A. latronum cluster close together in the morphospace. Even within species, morphological differentiation seems to occur roughly according to the pattern of genetic isolation, because the most divergent tooth shape within the geographical variation of $A$. peninsulae is displayed in the most distant locality, furthermore characterized by a divergent phylogroup (Sakka et al. 2010).

A notable exception is constituted by A. uralensis. As only representative of the subgenus Sylvaemus in the study, a strong coupling between genetic and morphometric differentiation would support the expectation of this species displaying the most divergent molar shape. Results evidence a reverse pattern, this species being close to the centre of the morphospace, together with $A$. draco and especially A. latronum.

This result may be due to ecological factors interfering with patterns of genetic divergence. Among species sharing a similar ecology, morphological differences have been shown to accumulate with time together with neutral genetic differentiation. In contrast, ecological shift can trigger a departure from this pattern by promoting morphological response to the new selective pressures (Polly 2001; Renaud et al. 2007; Adams et al. 2009).

Apodemus species tend to be generalist rodents associated with forest habitats (Corbet and Hill 1992; Smith and Xie 2008), an ecology that seems to be ancestral in the group and to have promoted a relative morphological stability in related species (Renaud et al. 2005). Yet, some ecological differentiation occurred even within this group. Species like A. draco and $A$. latronum are strongly associated with forests, whereas A. peninsulae and A. agrarius are more characteristics of open habitats (Giraudoux et al. 1998, 2008; Raoul et al. 2008; Vaniscotte et al. 2009). The sharing by distantly related species such as A. uralensis and the sister species A. draco and A. latronum of the generalist, forest-dweller ancestral habitat might have promoted a morphological stability either by fluctuating or even stabilizing selection (Polly 2001) whereas the ecological shift towards opened habitats would have triggered molar evolution in $A$. agrarius and $A$. peninsulae. Interestingly, despite their shift towards an apparently similar habitat, they diverged in opposite direction regarding molar shape. If the association between morphology and feeding behaviour appeared to be less straightforward than when considering mandible shape, some general trends tended to emerge in molar shape with regard to grinding performance. Broad teeth, compared with slender molars, have been interpreted as offering a wider surface of occlusion and hence allowing the grinding of more resistant matter such as vegetative parts of plants (Renaud and Michaux 2004; Renaud et al. 2005). If such trends can be transposed to variation among close species, this would suggest that despite sharing similar open habitats, $A$. peninsulae would favour a rather herbaceous diet, whereas $A$. agrarius might tend to feed on softer material such as grains or even animal preys (Butet and Delettre 2011).

\section{Size, a labile trait}

Size is known as a labile trait that can vary fast, in a partly plastic way, in relation to numerous genetic (Brockmann and Bevova 2002; Chan et al. 2012) and ecological factors (e.g. Brown et al. 1993; Damuth 1993; Lomolino 2005). Furthermore, size is a complex multifaceted trait that includes not only body size but also the size of each part of the animal. Whereas body size is likely submitted to selective pressure related to metabolism, for example, food availability or thermic requirements (Meiri and Dayan 2003; Meiri et al. 2005), size of the feeding apparatus may be submitted to pressures targeted on the size of the items to be consumed (Dayan et al. 1990; Dayan and Simberloff 1998). Our results evidence first an overall coupling of the size of various traits, being body size, mandible or molar size, pointing to a global scaling allowing the size of one morphological character to be used as a proxy for body size. Yet, mandible size appears as more closely related to body size than molar size, a result in agreement with previous studies (Renaud 2005) and that is likely attributable to the part of late growth occurring on the mandible and not on the molar. The relative uncoupling of molar size may also point to ecological 
processes driving a differentiation related to differential food utilization. An example is provided by the sister species A. latronum and A. draco, close in molar shape, because of their phylogenetic relatedness but highly different in molar size. In this case, the divergence in molar size might contribute to an evolutionary rapid segregation of close species in the way they utilize the resources, thanks to the lability of size-related traits.

\section{Molar size and shape participating to resource partitioning}

The coexistence of species sharing broadly similar ecologies, such as the Apodemus mice in China, would be favoured by a resource partitioning allowing a limitation of interspecific competition (Hutchinson 1959; Schoener 1974). A different exploitation of food resources is a major component of such a resource partitioning. It may be achieved by feeding on items of different size, hence selecting for different tooth size (Brown and Lieberman 1973; Dayan et al. 1990; Parra et al. 1999) or on items of various quality requiring different functional properties of the feeding apparatus (Dayan and Simberloff 1994). Both together may assure a complete sorting in the way even close species exploit apparently similar resources. The differentiation in molar morphology could contribute to such a resource partitioning, because species are segregated in a morphological space combining molar size and shape, most strikingly in the case of localities with sympatric species. Such a pattern was already documented in a group of related fossil rodents (Renaud et al. 1999) and therefore could constitute as a discrete but efficient way for similar species to exploit slightly different resources, allowing for the building and maintenance of a high diversity of related species.

\section{Conclusions}

Different traits, here mandibles and molars, provided discrepant pictures of the evolution of the Apodemus group in China. Each trait varied according to characteristic constraints and factors of differentiation. Mandible shape appeared prone to vary in response to local conditions, supporting the result of previous studies on various small mammals (Renaud 2005; Rychlik et al. 2006). In contrast, molar shape appeared to diverge in agreement with the expectations of a neutral genetic differentiation, both within and among species. Adaptation to slight differences in diet may further contribute to drive molar evolution. This differentiation in molar morphology likely accumulated together with time elapsed because divergence between populations and species. In cases of secondary contacts between differentiated species, it could contribute to achieve a subtle but efficient partitioning of food resources.

In apparent disagreement, no evidence was found of character displacement. Yet, character displacement is only expected to occur between species competing for the same resource. The divergence in molar size and shape accumulated over time as a consequence of isolation could have contributed to achieve a subtle resource partitioning even between related species, avoiding their competition for the same food resource, and hence the occurrence of character displacement. The complex landscape of China was prone to favour such a diversification, owing to both the numerous geographical barriers (deserts and mountain ranges) promoting isolation and a wide variation in climatic conditions (Zhai et al. 1999; Giraudoux et al. 2008).

\section{Acknowledgments}

We thank Andrea Cardini and an anonymous reviewer for their constructive comments. The collecting of samples was supported by Grant Number RO1 TW001565 from the Fogarty International Centre (the content is solely the authors' responsibility and does not necessarily represent the official views of the Fogarty International Centre or of the National Institutes of Health), the European Union (TS3-CT94-0270) and the French-Chinese Programme of Advanced Research (PRA E95-01). These programmes have been coordinated by P. Giraudoux and F. Raoul, University of Franche-Comté, France. This research was further supported by GDR 2474 CNRS 'Morphométrie et Evolution des Formes'.

\section{Résumé}

La différenciation de la dent, un indice pour comprendre la coexistence despèces? Le cas des mulots en Chine

Cinq espèces de mulots du genre Apodemus sont documentées en Chine, en allopatrie aussi bien qu'en sympatrie voire en syntopie. Elles partagent toutes une apparence externe similaire, des habitats de champs et forêts, et un comportement alimentaire généraliste. Les mécanismes permettant l'évitement de la compétition pour permettre la coexistence d'espèces aussi proches restent mal connus. Dans ce contexte, une analyse morphométrique de deux caractères impliqués dans l'alimentation (la mandibule et la molaire) a permis d'aborder les questions suivantes. (1) Les espèces divergent-elles dans la taille et/ou la forme de ces caractères, soutenant leur rôle dans la répartition des ressources ? (2) Ce patron de divergence reflète-t-il la différenciation génétique, suggérant la prédominance d'une divergence morphologique neutre? (3) Des phénomènes de déplacement de caractères peuvent-ils être mis en évidence, montrant l'existence de phénomènes de compétition actuels ? Les résultats ont mis en évidence que les deux caractères, mandibule et molaire, montraient différents patrons de divergence entre les espèces de mulots de Chine. La mandibule apparait comme variant avec des facteurs environnementaux locaux masquant les patrons phylogénétiques et écologiques. En revanche, la différenciation de forme de la molaire semble suivre dans les grandes lignes la divergence génétique. Taille et forme de la molaire séparent les différentes espèces dans l'espace morphologique, suggérant une participation à la répartition des ressources entre ces espèces, mais le déplacement de caractère n'a pas été mis en évidence. Ceci suggère que la différenciation des espèces s'est surtout produite suite à l'isolement entre populations et espèces, facilité par le paysage complexe de la Chine.

\section{References}

Adams DC, West ME, Collyer ML (2007) Location-specific sympatric morphological divergence as a possible response to species interactions in West Virginia Plethodon salamander communities. J Anim Ecol 76:289-295.

Adams DC, Bern CM, Kozak KH, Wiens JJ (2009) Are rates of species diversification correlated with rates of morphological evolution? Proc R Soc London B 276:2729-2738.

Amori G, Gippoliti S (2001) Identifing priority ecoregions for rodent conservation at the genus level. Oryx 35:158-165.

Brockmann GA, Bevova MR (2002) Using mouse models to dissect the genetics of obesity. Trends Ecol Evol 18:367-376.

Brown JH, Lieberman GA (1973) Resource utilization and coexistence of seed-eating desert rodents in sand dune habitats. Ecology 54:788-797. Brown JH, Marquet PA, Taper ML (1993) Evolution of body size: consequences of an energetic definition of fitness. Am Nat 142:573-584. Butet A., Delettre YR (2011) Diet differentiation between European arvicoline and murine rodents. Acta Theriologica 56:297-304.

Cardini A, O’Higgins P (2004) Patterns of morphological evolution in Marmota (Rodentia, Sciuridae): geometric morphometrics of the cranium in the context of marmot phylogeny, ecology and conservation. Biol J Linn Soc 82:385-407.

Cardini A, Thorington RWJ, Polly PD (2007) Evolutionary acceleration in the most endangered mammal of Canada: speciation and 
divergence in the Vancouver Island marmot (Rodentia, Sciuridae). J Evol Biol 20:1833-1846.

Chan YF, Jones FC, McConnell E, Bryk J, Bünger L, Tautz D (2012) Parallel selection mapping using artificially selected mice reveals body weight control loci. Curr Biol 22:794-800.

Corbet GB, Hill JE (1992) The Mammals of the Indomalayan Region: A Systematic Review. Natural History Museum publications, Oxford University Press, Oxford.

Crampton JS (1995) Elliptic Fourier shape analysis of fossil bivalves: some practical considerations. Lethaia 28:179-186.

Damuth J (1993) Cope's rule, the island rule and the scaling of mammalian population density. Nature 365:748-750.

Darviche D, Orsini P (1982) Critères de différenciation morphologique et biométrique de deux espèces de souris sympatriques : Mus spretus et Mus musculus domesticus. Mammalia 46:205-218.

Darviche D, Orth A, Michaux J (2006) Mus spretus and M. musculus (Rodentia, Mammalia) en zone méditerranéenne: différenciation biométrique et morphologique: application à des fossils marocains pléistocènes. Mammalia 70:90-97.

Dawson MR, Marivaux L, Li C-k, Beard KC, Métais G (2006) Laonastes and the "Lazarus Effect" in Recent Mammals. Science 311:1456-1458.

Dayan T, Simberloff D (1994) Morphological relationships among coexisting heteromyids: an incisive dental character. Am Nat 143:462-477.

Dayan T, Simberloff D (1998) Size patterns among competitors: ecological character displacement and character release in mammals, with special reference to island populations. Mammal Rev 28:99-124.

Dayan T, Simberloff D, Tchernov E, Yom-Tov Y (1990) Feline canines: community-wide character displacement among the small cats of Israel. Am Nat 136:39-60.

Felsenstein J (1981) Evolutionary trees from DNA sequences: a maximum likelihood approach. J Mol Evol 17:368-376.

Giraudoux P, Quéré JP, Delattre P, Bao G, Wang X, Shi D, Vuitton D, Craig PS (1998) Distribution of small mammals along a deforestation gradient in southern Gansu, central China. Acta Theriologica 43:349-362.

Giraudoux P, Zhou H, Quéré J-P, Raoul F, Delattre P, Volobouev V, Déforêt T, Ito A, Mamuti W, Scheifler R, Craig PS (2008) Small mammal assemblages and habitat distribution in the northern Junggar Basin, Xinjiang, China : a pilot survey. Mammalia 72:309-319.

Guindon S, Gascuel O (2003) A simple fast and accurate algorithm to estimate large phylogenies by maximum likelihood. Syst Biol 52:696-704.

Huchon D, Chevret P, Jordan U, Kilpatrick CW, Ranwez V, Jenkins PD, Brosius J, Schmitz J (2007) Multiple molecular evidences for a living mammalian fossil. Proc Natl Acad Sci, USA 104:7495-7499.

Hutchinson GE (1959) Homage to Santa Rosalia or Why are there so many kinds of animals? Am Nat 93:145-159.

Kuhl FP, Giardina CR (1982) Elliptic Fourier features of a closed contour. Comput Graph Image Process 18:259-278.

Liu J, Ouyang Z, Pimm SL, Raven PH, Wang X, Miao H, Han N (2003) Protecting China's Biodiversity. Science 300:1240-1241.

Lomolino MV (2005) Body size evolution in insular vertebrates: generality of the island rule. J Biogeogr 32:1683-1699.

Meiri S, Dayan T (2003) On the validity of Bergmann's rule. J Biogeogr 30:331-351.

Meiri S, Dayan T, Simberloff D (2005) Biogeographical patterns in the Western Palearctic: the fasting-endurance hypothesis and the status of Murphy's rule. J Biogeogr 32:369-375.

Michaux JR, Chevret P, Filipucci M-G, Macholan M (2002) Phylogeny of the genus Apodemus with a special emphasis on the subgenus Sylvaemus using the nuclear IRBP gene and two mitochondrial markers: cytochrome b and 12S rRNA. Mol Phylogenet Evol 23:123-136.

Michaux J, Chevret P, Renaud S (2007) Morphological diversity of Old World rats and mice (Rodentia, Muridae) mandible in relation with phylogeny and adaptation. J Zool Syst Evol Res 45:263-279.

Navarro N, Zararain X, Montuire S (2004) Effects of morphometric descriptor change on statistical classification and morphospaces. Biol J Linn Soc 83:243-260.
Parra V, Loreau M, Jaeger J-J (1999) Incisor size and community structure in rodents: two tests of the role of competition. Acta Oecol 20:93-100

Polly PD (2001) On morphological clocks and paleophylogeography: towards a timescale for Sorex hybrid zones. Genetica 112-113:339357.

Posada D, Crandall KA (1998) Modeltest: testing the model of DNA substitution. Bioinformatics 14:817-818.

Raoul F, Pleydell D, Quéré JP, Vaniscotte A, Rieffel D, Takahashi K, Bernard N, Wang J, Dobigny T, Galbreath KE, Giraudoux P (2008) Small assemblage response to deforestation and afforestation in central China. Mammalia 72:320-332.

Renaud S (2005) First upper molar and mandible shape of wood mice (Apodemus sylvaticus) from northern Germany: ageing, habitat and insularity. Mammalian Biol 70:157-170.

Renaud S, Auffray J-C (2010) Adaptation and plasticity in insular evolution of the house mouse mandible. J Zool Syst Evol Res 48:138-150.

Renaud S, Michaux JR (2003) Adaptive latitudinal trends in the mandible shape of Apodemus wood mice. J Biogeogr 30:1617-1628.

Renaud S, Michaux J (2004) Parallel evolution in molar outline of murine rodents: the case of the extinct Malpaisomys insularis (Eastern Canary Islands). Zool J Linn Soc 142:555-572.

Renaud S, Michaux JR (2007) Mandibles and molars of the wood mouse, Apodemus sylvaticus (L.): integrated latitudinal signal and mosaic insular evolution. J Biogeogr 34:339-355.

Renaud S, Millien V (2001) Intra- and interspecific morphological variation in the field mouse species Apodemus argenteus and A. speciosus in the Japanese archipelago: the role of insular isolation and biogeographic gradients. Biol J Linn Soc 74:557-569.

Renaud S, Michaux J, Jaeger J-J, Auffray J-C (1996) Fourier analysis applied to Stephanomys (Rodentia, Muridae) molars: nonprogressive evolutionary pattern in a gradual lineage. Paleobiology 22:255-265.

Renaud S, Michaux J, Mein P, Aguilar J-P, Auffray J-C (1999) Patterns of size and shape differentiation during the evolutionary radiation of the European Miocene murine rodents. Lethaia 32: 61-71.

Renaud S, Michaux J, Schmidt DN, Aguilar J-P, Mein P, Auffray J-C (2005) Morphological evolution, ecological diversification and climate change in rodents. Proc R Soc London, B 272:609-617.

Renaud S, Auffray J-C, Michaux J (2006) Conserved phenotypic variation patterns, evolution along lines of least resistance, and departure due to selection in fossil rodents. Evolution 60:17011717

Renaud S, Chevret P, Michaux J (2007) Morphological vs. molecular evolution: ecology and phylogeny both shape the mandible of rodents. Zoolog Scr 36:525-535.

Renaud S, Auffray J-C, de La Porte S (2010) Epigenetic effects on the mouse mandible: common features and discrepancies in remodeling due to muscular dystrophy and response to food consistency. BMC Evol Biol 20:18.

Rychlik L, Ramalhinho G, Polly PD (2006) Response to environmental factors and competition: skull, mandible and tooth shapes in Polish water shrews (Neomys, Soricidae, Mammalia). J Zool Syst Evol Res 44:339-351.

Sakka H, Quéré J-P, Kartavtseva I, Pavlenko M, Chelomina G, Atopkin D, Bogdanov A, Michaux JR (2010) Comparative phylogeography of four Apodemus species (Mammalia: Rodentia) in the Asian Far East: evidence of Quaternary climatic changes in their genetic structure. Biol J Linn Soc 100:797-821.

Schoener TW (1974) Resource partitioning in ecological communities. Science 185:27-39.

Sheets HD, Covino KM, Panasiewicz JM, Morris SR (2006) Comparison of geometric morphometric outline methods in discrimination of age-related differences in feather shape. Front Zool 3:15.

Smith A, Xie Y (2008) A Guide to the Mammals of China. Princeton University Press, Princeton and Oxford.

Sodhi NS, Koh LP, Brook BW, Ng PKL (2004) Southeast Asian biodiversity: an impending disaster. Trends Ecol Evol 19:654-660. Suzuki H, Filippucci MG, Chelomina GN, Sato JJ, Serizawa K, Nevo E (2008) A biogeographic view of Apodemus in Asia and Europe 
inferred from nuclear and mitochondrial gene sequences. Biochem Genet 46:329-346.

Vaniscotte A, Pleydell D, Raoul F, Quéré J-P, Jiamind Q, Wang Q,

Tiaoying L, Bernardas N, Coeurdassier M, Delattre P, Takahashic

K, Weidmanne J, Giraudoux P (2009) Modelling and spatial discrimination of small mammal assemblages: an example from western Sichuan (China). Ecol Model 220:1218-1231.

Zhai P, Sun A, Ren F, Liu X, Gao B, Zhang Q (1999) Changes of climate extremes in China. Climatic change 42:203-218. 